\title{
Short-Term Motor Compensations to Denervation of Feline Soleus and Lateral Gastrocnemius Result in Preservation of Ankle Mechanical Output during Locomotion
}

\author{
Boris I. Prilutsky ${ }^{a}$ Huub Maas ${ }^{c}$ Margarita Bulgakova ${ }^{a}$ Emma F. Hodson-Tole ${ }^{d}$ \\ Robert J. Gregor ${ }^{a, b}$ \\ ${ }^{a}$ Center for Human Movement Studies, School of Applied Physiology, Georgia Institute of Technology, Atlanta, Ga., \\ and ${ }^{b}$ Division of Biokinesiology and Physical Therapy, University of Southern California, Los Angeles, Calif., USA; \\ 'Research Institute MOVE, Faculty of Human Movement Sciences, VU University, Amsterdam, The Netherlands; \\ dInstitute of Biomedical Research into Human Health and Movement, Manchester Metropolitan University, \\ Manchester, UK
}

\section{Key Words}

Nerve injury · Motor compensation • Joint moment •

Joint power $\cdot$ Locomotion

\begin{abstract}
Denervation of selected ankle extensors in animals results in locomotor changes. These changes have been suggested to permit preservation of global kinematic characteristics of the hindlimb during stance. The peak ankle joint moment is also preserved immediately after denervation of several ankle extensors in the cat, suggesting that the animal's response to peripheral nerve injury may also be aimed at preserving ankle mechanical output. We tested this hypothesis by comparing joint moments and power patterns during walking before and after denervation of soleus and lateral gastrocnemius muscles. Hindlimb kinematics, ground reaction forces and electromyographic activity of selected muscles were recorded during level, downslope $(-50 \%)$ and upslope (50\%) walking before and $1-3$ weeks after nerve denervation. Denervation resulted in increased activity of the intact medial gastrocnemius and plantaris muscles, greater ankle dorsiflexion, smaller knee flexion, and the preservation of the peak ankle moment during stance. Surprisingly,
\end{abstract}

ankle positive power generated in the propulsion phase of stance was increased (up to 50\%) after denervation in all walking conditions $(p<0.05)$. The obtained results suggest that the short-term motor compensation to denervation of lateral gastrocnemius and soleus muscles may allow for preservation of mechanical output at the ankle. The additional mechanical energy generated at the ankle during propulsion can result, in part, from increased activity of intact synergists, the use of passive tissues around the ankle and by the tendon action of ankle two-joint muscles and crural fascia.

Copyright $\odot 2011$ S. Karger AG, Basel

Abbreviations used in this paper

EMG electromyographic

LG lateral gastrocnemius

MG medial gastrocnemius

MTP metatarsophalangeal

MTU muscle tendon unit

$\mathrm{PL} \quad$ plantaris

SD standard deviation

SO soleus

\section{KARGER}

(๑) 2011 S. Karger AG, Basel

Fax +41 613061234

E-Mail karger@karger.ch

www.karger.com
Accessible online at: www.karger.com/cto
Dr. Boris I. Prilutsky

Georgia Institute of Technology

School of Applied Physiology

281 Ferst Drive, Atlanta, GA 30332-0356 (USA)

Tel. +1 404894 7659, Fax +1 404727 6256, E-Mail boris.prilutsky@ap.gatech.edu 


\section{Introduction}

Damage to peripheral nerves as a result of trauma is a rather frequent event that incapacitates thousands of people around the world [Scholz et al., 2009]. This injury often requires medical intervention including microsurgery and long-term postoperative rehabilitation [Portincasa et al., 2007]. A recent survey of $>300$ surgical institutions in Africa, Asia, Australia, Europe, South America and the United States indicates that most of the institutions treat $>3,000$ patients with peripheral nerve injury each year [Scholz et al., 2009].

Despite a long history of research into the mechanisms of peripheral nerve injury and regeneration, see e.g., Sunderland [1990], and recent advances in microsurgery, see e.g., Kline [1990], and tissue engineered constructs, see e.g., Chalfoun et al. [2006], outcomes of nerve repair are still unsatisfactory, especially in patients with complete transection of mixed nerves at proximal locations [Noble et al., 1998; Lundborg and Rosen, 2007; Scholz et al., 2009]. The reasons for poor recovery may include relatively slow nerve regeneration speed (1-2 mm/day) [Buchthal and Kuhl, 1979], axonal misdirection [English, 2005; Madison et al., 2007], death of up to $50 \%$ of cutaneous sensory cells in the dorsal root ganglion $[\mathrm{Hu}$ and McLachlan, 2003; Welin et al., 2008], and a complete loss of length-dependent feedback from reinnervated muscles [Cope et al., 1994; Abelew et al., 2000; Maas et al., 2007].

About $2.5 \%$ of peripheral nerve injuries are unrepairable [Scholz et al., 2009] which leads to paralysis of injured muscles. These patients must rely on muscle redundancy (the existence of synergists with similar functions) and neural plasticity permitting alternative motor strategies to accomplish everyday tasks. Studies in animals have demonstrated that within days after peripheral nerve injury there are changes in electromyographic (EMG) activity of intact synergists and movement kinematics. For instance, denervation of selected ankle extensors in the cat - e.g., soleus (SO) and lateral gastrocnemius (LG) - led to an increase in activity of the remaining intact major ankle extensors [Pearson et al., 1999; Prilutsky et al., 2006; Frigon and Rossignol, 2008; Donelan et al., 2009; Maas et al., 2010]. This enhancement in muscle activity is accompanied by a marked increase in the ankle angle yield (i.e. ankle dorsiflexion) and a decrease in the knee flexion during stance of level and slope walking [Pearson et al., 1999; Maas et al., 2007; Donelan et al., 2009; Maas et al., 2010]. These immediate changes in motor pattern were suggested to be mediated by proprioceptive afferent signals, modifications of central drive to the muscles and changes in feedback gains [Pearson and Misiaszek, 2000; Gritsenko et al., 2001; Frigon and Rossignol, 2008; Donelan et al., 2009; Maas et al., 2010].

In the previous studies, relatively little attention has been paid to the question as to whether the observed locomotor changes in response to paralysis of selected muscles have any meaningful compensatory significance. The rise in stance-related activity of intact medial gastrocnemius (MG) muscle after denervation of its ankle synergists may help preserve the peak magnitude of the ankle extensor moment [Prilutsky et al., 2006; Donelan et al., 2009]. The emergence of a second EMG burst of MG at the stance-swing transition after partial denervation of the hamstrings in the cat appears functionally appropriate in assisting knee flexion [Tachibana et al., 2006]. The reduction in knee flexion after partial denervation of ankle extensors resulting in additional ankle yield does not appear to be functionally useful at a first glance. According to previous observations, the above kinematic changes enable the animal to maintain pre-injury trajectories of limb orientation and limb length [Chang et al., 2009] and hip height and limb orientation at paw contact and paw off [Maas et al., 2007], permitting a more symmetric gait.

There is another possible explanation for the documented kinematic changes at the ankle and knee joints immediately after partial denervation of ankle extensors, which is also consistent with purposeful enhancement of EMG in intact synergists. A greater ankle yield and smaller knee flexion in stance permit a greater length of the muscle tendon unit (MTU) at which intact and denervated multi-joint MG, LG and plantaris (PL) operate [Maas et al., 2010]. This increase in MTU length might have several advantages for promoting ankle extension including: (1) slack in the passive structures of the muscles could be taken up, and thus, the passive tissue (possibly including denervated muscles) would contribute more to the ankle extension moment; (2) longer lengths of MTUs of two-joint muscles during stance could enhance the so-called tendon action of these muscles, i.e. transfer of energy between the ankle and knee, increasing energy generation and absorption at the ankle by proximal muscles [Bobbert et al., 1986; Prilutsky and Zatsiorsky, 1994], and (3) the crural fascia could be engaged more in generation of the ankle extension moment [Carrasco and English, 1999; Stahl, 2010].

We hypothesized that the kinematic and EMG changes observed soon after denervation of selected ankle extensors permit the preservation of the ankle mechanical output during locomotion. The goal of this study was to compare joint moments and power at the ankle and other hindlimb joints (knee and hip) before and after dener- 
Table 1. Characteristics of animals and walking cycles used for mechanical analysis

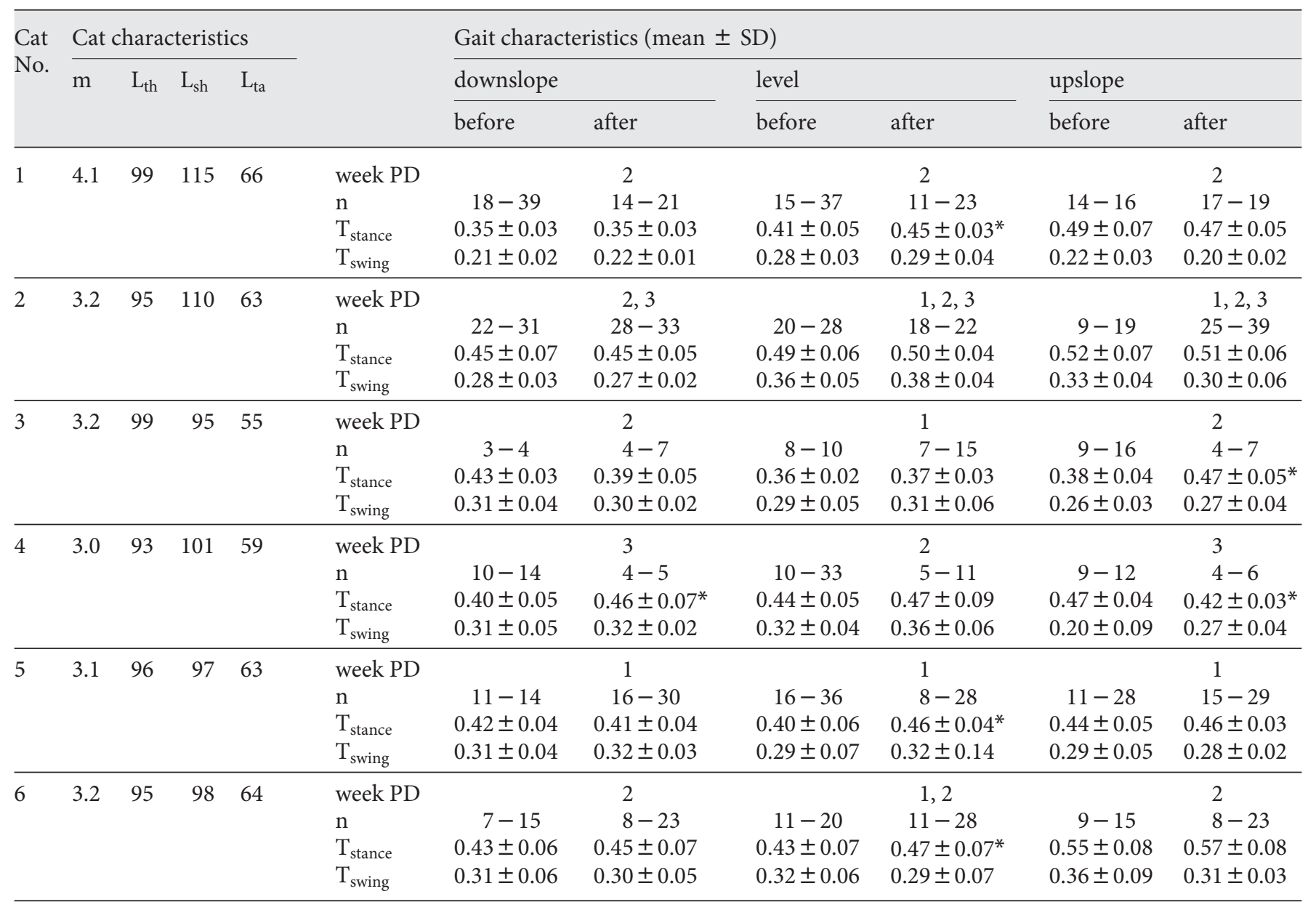

$\mathrm{m}=$ Body mass given in $\mathrm{kg} ; \mathrm{L}_{\mathrm{th}}=$ thigh length in $\mathrm{mm} ; \mathrm{L}_{\mathrm{s}}=$ shank length in $\mathrm{mm} ; \mathrm{L}_{\mathrm{ta}}=$ tarsal length in $\mathrm{mm}$; week PD = weeks after denervation when the measurements were taken; $\mathrm{n}=$ range of number of cycles used for mechanical analysis in different walking conditions; $\mathrm{T}_{\text {stance }}=$ stance time in $\mathrm{s} ; \mathrm{T}_{\text {swing }}=$ swing time in $\mathrm{s}$.

${ }^{*} \mathrm{p}<0.05$, stance duration significantly different from the value before self-reinnervation in individual animals.

vation of SO and LG muscles. A better understanding of compensatory responses of the neuromuscular system to peripheral nerve injury will help in developing evidencebased rehabilitation procedures for patients with paralysis of selected muscles. Preliminary results of this work have been presented in an abstract form [Prilutsky et al., 2006; Bulgakova et al., 2010].

\section{Methods}

In these series of experiments, 6 female adult cats (Felis catus; table 1) were studied. The experimental and surgical procedures were consistent with US Public Health Service Policy on Humane Care and Use of Laboratory Animals and approved by the Insti- tutional Animal Care and Use Committee of Georgia Institute of Technology.

Prior to surgeries and data collection, each cat was trained using methods of operant conditioning with food awards to walk along a custom-made Plexiglas-enclosed wooden walkway $(3.0 \times$ $0.4 \mathrm{~m}$ ) with up to 3 force plates $(2$ plates, $16 \times 11 \mathrm{~cm}$; 1 plate, 11 $\times 7 \mathrm{~cm}$; Bertec Corporation, Columbus, Ohio, USA) embedded in the walkway floor. The floor and force plates were covered separately with rubberized material to prevent slippage. The walkway was set up at 3 walking conditions: level (0\%), downslope $\left(-50 \%\right.$ or $\left.-27^{\circ}\right)$ and upslope $\left(50 \%\right.$ or $\left.27^{\circ}\right)$.

\section{Surgeries}

After completion of locomotor training (lasting 3-6 weeks) and initial locomotion data collection (necessary for evaluating effects of electrode implantations on walking mechanics, see below), each animal underwent a first survival surgery under gen- 
eral anesthesia and aseptic conditions to implant EMG electrodes in selected ankle extensor muscles. The cat was anesthetized using ketamine (10 mg/kg, s.c.), atropine $(0.05 \mathrm{mg} / \mathrm{kg}$, s.c.) and isoflurane (inhalation, 5\%). Subsequently, the cat was intubated and anesthesia was maintained with isoflurane (1-3\%). The animal was continuously monitored for temperature, respiration, heart rate and blood pressure throughout the surgery. Before making incisions, the skin overlying dorsal aspects of the right hindlimb and the skull was shaved and cleaned with a surgical disinfectant. Teflon-insulated multi-stranded stainless steel wires $(100 \mu \mathrm{m}$ diameter; Conner Wire, Chatsworth, Calif., USA) were passed subcutaneously along the back from a multi-pin amphenol connector mounted on the skull (with four stainless steel screws and dental cement) to a skin incision overlying muscles of interest in the right hindlimb: SO, LG, MG (in cats No. 3-6) and SO, LG, MG and PL (in cats No. 1 and 2). A portion of each pair of wires with a small strip of insulation (approximately $2 \mathrm{~mm}$ ) removed was inserted with a hypodermic needle in the mid-belly of each muscle and fixed at an inter-electrode distance of 3-4 mm. After implantation of EMG electrodes and their validation using mild electrical stimulation, skin incisions were closed, pain medication administered (fentanyl transdermal patch, $2-25 \mu \mathrm{g} / \mathrm{h}$ and/or buprenorphine, s.c., $0.01 \mathrm{mg} / \mathrm{kg}$, or ketoprofen, $2 \mathrm{mg} / \mathrm{kg}$, s.c.) and anesthesia stopped. The animal recovered for 1-2 weeks with the pain medication administered for at least 3 days and antibiotics (cefovecin, $8 \mathrm{mg} / \mathrm{kg}$, s.c., or ceftiofur, $4 \mathrm{mg} / \mathrm{kg}$, s.c.) for 10 days. Locomotion experiments followed the EMG electrode implantation and lasted typically for up to 3 weeks (see below). No signs of pain or lameness during walking were detected after implantation of EMG electrodes with locomotor patterns recorded after implantation indistinguishable from those collected before surgery.

Once collection of baseline locomotion and EMG data was completed, the second survival surgery was conducted to cut and reconnect the branch of the tibial nerve innervating SO and LG. The aseptic conditions, anesthesia and animal monitoring and postsurgery pain management were the same as in the first surgery. A longitudinal skin incision was made in the popliteal region of the right hindlimb and the exposed fat pad reflected aside by blunt dissection. The LG-SO nerve was identified and a small portion $(2-4 \mathrm{~mm})$ cleared of surrounding tissue. The nerve was cut with sharp scissors between the branch point of the tibial nerve and the entry point to LG. Completeness of SO and LG denervation was tested with mild electrical stimulation of the proximal nerve stump. Subsequently, proximal and distal nerve stumps were aligned to their original position and secured in place using fibrin glue (equal parts of thrombin and a 1:1 mixture of fibrin and fibronectin; Sigma-Aldrich, St. Louis, Mo., USA) [English et al., 2005]. The cat was allowed to recover for 3-5 days before locomotion experiments resumed.

The repair of the cut peripheral nerve using fibrin glue (or 10-0 suture as used by us previously) allows for reinnervation of cat ankle extensor muscles - first signs of detectable EMG emerge in 4-5 weeks [Gregor et al., 2003; Prilutsky et al., 2006; unpubl. data]. In this manuscript, we report data obtained during the first 3 weeks after nerve cut and repair when SO and LG were still in a state of paralysis.

\section{Locomotion Experiments}

Each cat was tested in 3 series of experiments, i.e. (1) before EMG electrode implantations, (2) after implantations and before denervation, and (3) after denervation, and in 3 locomotion conditions, i.e. level, downslope and upslope walking. Before first testing in each of the 3 series of experiments, the cats were sedated (dexmedetomidine, $40-60 \mu \mathrm{g} / \mathrm{kg}$, s.c.) and the right hindlimb was shaved. The length of each hindlimb segment (pelvis, thigh, shank, tarsals, digits) was measured using an anthropometer (table 1). Following shaving and segment measurements, antipamezole (same dose as dexmedetomidine) was administered to reverse sedation.

Prior to recordings, small ( 6 or $9 \mathrm{~mm}$ ) reflective markers were placed on the anatomical landmarks of the right hindlimb (the iliac spine, greater trochanter, lateral femoral epicondyle, lateral malleolus, 5th metatarsophalangeal (MTP) joint and the distal end of the 5th digit; see cat hindlimb diagram in fig. 1a) using a double-sided adhesive tape. Marker positions during locomotion were recorded in $3 \mathrm{D}$ by a 6-camera motion capture system Vicon (Vicon Motion Systems, UK) at a sampling rate of $120 \mathrm{~Hz}$. Positional data were recorded synchronously with the 3 components of the ground reaction force vector and coordinates of its point of application $(360 \mathrm{~Hz}$; Bertec Corporation, Columbus, Ohio, USA) and with EMG signals sampled at 3,000 $\mathrm{Hz}$ from SO, LG, MG and PL. EMG signals were collected using a 16-conductor shielded flexible cable that was attached to the head mounted connector. The recorded signals were band-pass filtered $(30-1,000 \mathrm{~Hz})$ and amplified. During each session, 30-60 trials of walking were recorded. Only trials during which the cat moved with a steady speed and hit at least one force plate with the right hindlimb were used for analysis. Walking cycles that were too fast (stance duration $<300 \mathrm{~ms}$ ) or too slow ( $>650 \mathrm{~ms}$ ) were not analyzed. Postdenervation locomotor testing was conducted for 3-5 days each week starting from day 4 or 5 (when possible; week 1) and continued for 12 weeks or longer. In this report, we present results obtained in weeks 1 and 2 after denervation (cats No. 1, 3, 5, 6; table 1). Data obtained in week 3 were also included into the dataset for 2 animals (cats No. 2 and 4) because their gait in weeks 1 and 2 was unsteady or too slow, so an insufficient number of good walking cycles were collected. Since no SO and LG EMG activity could be detected in the analyzed postdeneravation walking cycles, the postdenervation data were treated as a single dataset representing short-term effects of SO and LG paralysis.

\section{Data Analysis}

Kinematics

Marker coordinates in the sagittal plane were low-pass filtered (4th-order, zero-lag Butterworth filter, with a cutoff frequency of 5-8 Hz). Knee marker position was recalculated from hip and ankle coordinates and length of thigh and shank segments to reduce influence of skin movement around the knee. Linear and angular segment displacements, joint angles as well as their first (velocity) and second (acceleration) time derivatives were computed using the method of finite differences; for details of kinematic analysis and definitions of body segments and joint angles, see Prilutsky et al. [2005], Gregor et al. [2006] and Maas et al. [2007] (fig. 1a).

\section{Kinetics}

Mass and moment of inertia with respect to the frontal axis through the center of mass of each hindlimb segment were obtained from the cat mass and the measured segment length (table 1) by means of the regression equations [Hoy and Zernicke, 


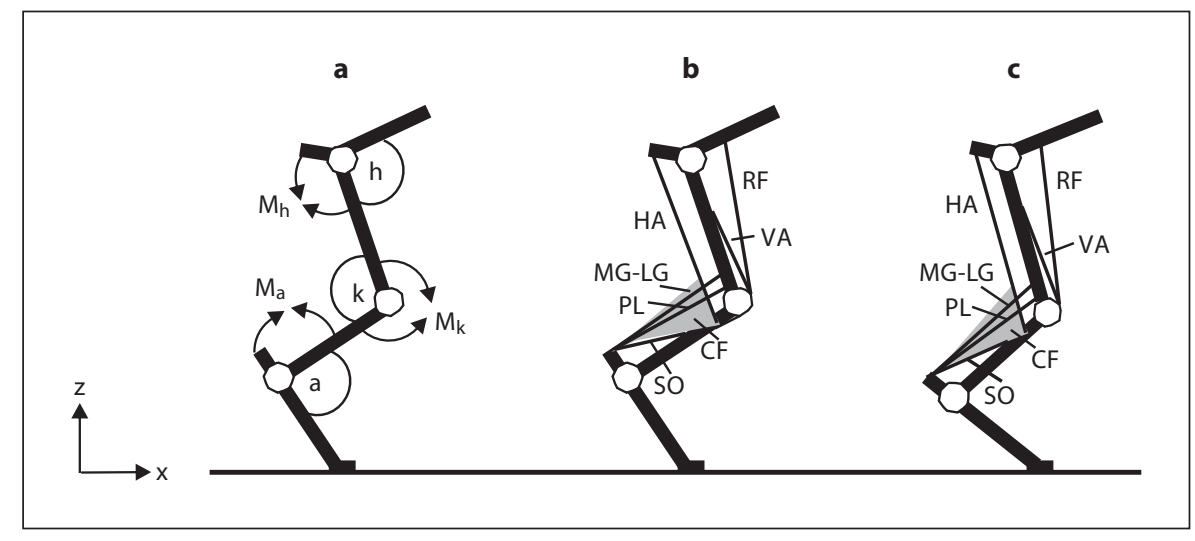

Fig. 1. Schematic representations of the cat hindlimb. a Definitions of joint angles and joint moment directions. Letters $\mathrm{a}, \mathrm{k}$ and $\mathrm{h}$ and the corresponding arcs denote ankle, knee and hip joint angles; symbols $\mathrm{M}_{\mathrm{a}}, \mathrm{M}_{\mathrm{k}}$ and $\mathrm{M}_{\mathrm{h}}$ and the corresponding arrows indicate the extension direction of moment and angular velocity at the ankle, knee and hip joints, respectively. Axes $\mathrm{z}$ and $\mathrm{x}$ indicate the normal and tangential directions with respect to surface. b Schematic of the cat hindlimb with selected muscles depicted in mid-stance of level walking before partial denervation of ankle extensors. $\mathrm{VA}=$ Vasti; $\mathrm{RF}=$ rectus femoris; $\mathrm{HA}=$ hamstrings;
$\mathrm{CF}=$ crural fascia. Schematic of the crural fascia (shaded triangle) depicts its two features: origin on distal portion of the hamstrings and attachment to the calcaneus. $\mathbf{c}$ The same schematic as in $\mathbf{b}$ shown for mid-stance of walking after denervation of SO and LG. Note a greater ankle dorsiflexion and smaller knee flexion. As a consequence, the lengths of MG, LG, PL and crural fascia are increased and enable increasing the passive ankle extensor moment and energy transfer between the ankle and knee joints (for further explanations, see Discussion).
1985]. The resultant moments of force at hindlimb joints in the sagittal plane were computed using a standard inverse dynamics analysis described previously [Manter, 1938; Fowler et al., 1993; McFadyen et al., 1999; Prilutsky et al., 2005; Gregor et al., 2006]. Briefly, each hindlimb segment was considered in isolation with external forces and moments applied at the distal and proximal joints. The Newton-Euler dynamic equations of motion written for the most distal segment (digits), known segment mass-inertia parameters and the measured ground reaction forces (the normal and tangential components to walking surface), as well as linear and angular segment accelerations enabled calculations of the joint forces and joint moment at the proximal (MTP) joint. Analogous calculations were conducted to compute the forces and moment applied at the proximal joint (ankle) of the next tarsal segment; in these calculations, the role of external moment and forces at the distal joint played the MTP joint moment and force components multiplied by -1 . The calculations were repeated for the next two segments (shank and thigh), and joint moments of force at the knee and hip were calculated. According to selected sign convention, positive joint moments and velocities corresponded to joint extension (fig. 1a).

Joint power was computed as the product of the joint moment and joint angular velocity. Positive values of joint power indicate generation of mechanical energy at the joint, negative - energy absorption.

Measured ground reaction forces (tangential and normal components) and computed joint moments and power during each walking cycle were time normalized separately for the stance and swing phases. These kinetic variables were averaged for each $0.5 \%$ of stance and $1 \%$ of swing across walking cycles of each cat and then across all cats for each walking condition. Kinetic data were checked for outliers - a variable in a particular cycle was removed from the data set if its values were outside of \pm 2 standard deviation (SD) of the mean. Such outliers were likely resulted from unsteady gait or measurement artifacts.

Values of the ground reaction force, joint moments and power were normalized by the animal mass, and maximum and minimum values of these variables were determined for statistical analysis.

\section{Electromyography}

EMG analysis was described previously [Gregor et al., 2006; Maas et al., 2010] and is only briefly outlined here. EMG band-pass filtered signals ( $30-1,000 \mathrm{~Hz}, 3 \mathrm{~dB}$ ) were full-wave rectified (fig. 2). EMG burst onset and offset times were determined using a criterion of $2 \mathrm{SD}$; when the EMG magnitude exceeded $2 \mathrm{SD}$ of the mean EMG during muscle silent periods (most of the swing phase) for at least $50 \mathrm{~ms}$, the muscle was considered active. The onset and offset times enabled identification of EMG bursts. The mean magnitude and duration of the bursts were computed and the mean magnitude normalized to the maximum of the mean EMG magnitudes found for each cat across all trials and walking conditions.

\section{Statistics}

Mean and SD of minimum and maximum values of ground reaction forces, joint moments and powers during the stance phase as well as the EMG burst duration and mean magnitude were computed for all walking conditions before and after muscle denervation. Pre- and postdenervation values of the above characteristics were tested for statistically significant differences within each cat and across all cats using the Student $t$ test for independent variables. Significance level was set at 0.05 . In the statistical analysis, 
Fig. 2. Examples of rectified EMG activity of ankle extensor muscles before and 1 week after denervation of SO and LG muscles during downslope (-50\%), level $(0 \%)$ and upslope $(50 \%)$ walking of cat No. 5. Only 3 ankle extensors were recorded in cat No. 5: SO, MG and LG. Horizontal lines under $\mathrm{MG}$ recordings indicate stance phases.

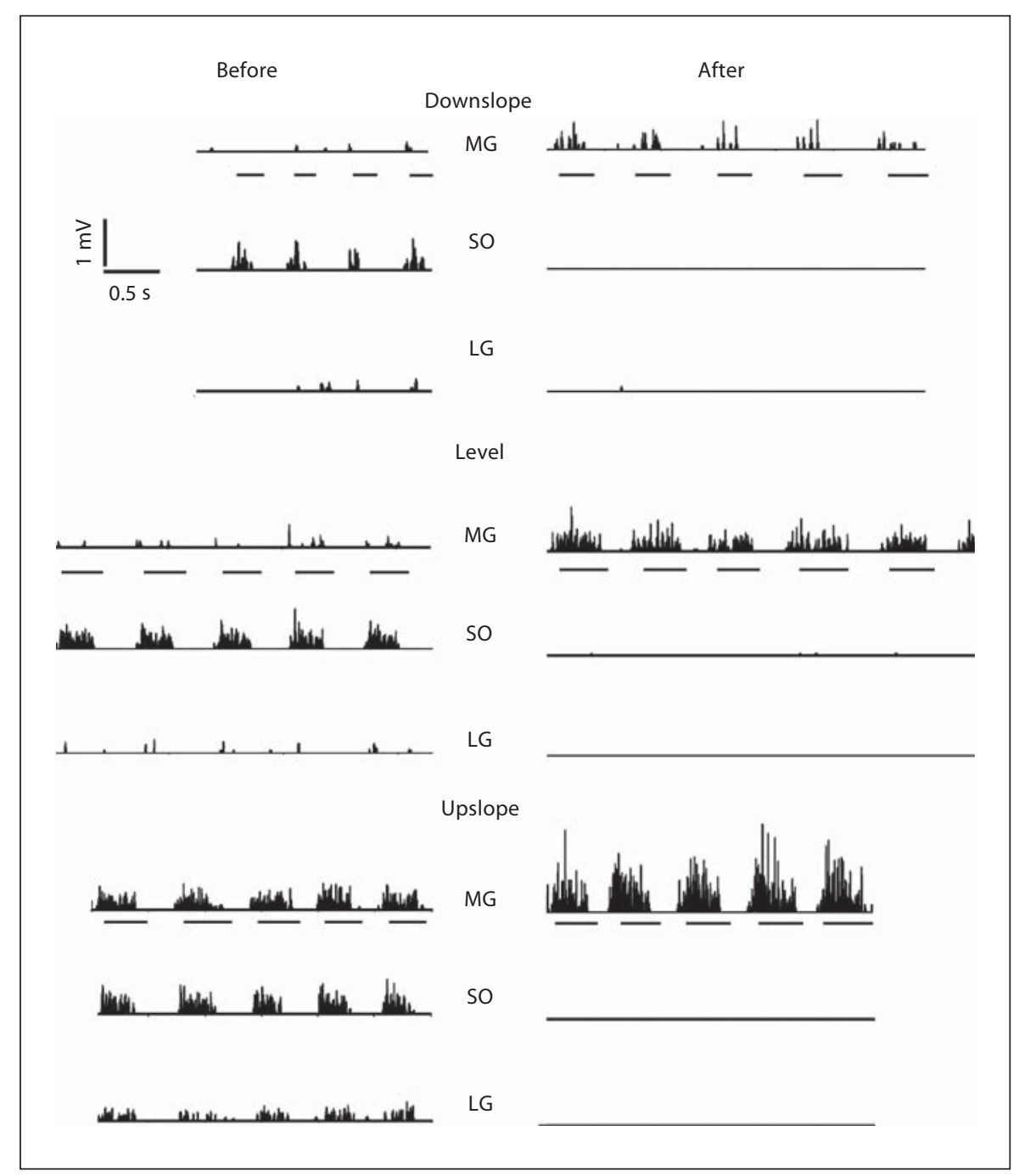

stance duration (indicating walking speed) was not used as a covariate because the stance duration increased after denervation only by about $10 \%$ in a small number of cases ( 6 out of 18 ; table 1 ). Also, the observed increase in EMG activity of the intact ankle extensors and in the ankle joint moment and power magnitude were opposite to changes that are expected from longer stance times (slower walking speed; see Results and Discussion).

\section{Results}

Changes in EMG Activity of Selected Ankle Extensors after Denervation of SO and LG Muscles

Prior to denervation of SO and LG, the recorded muscles demonstrated typical stance-related EMG activity (fig. 2). SO EMG was prominent during all walking conditions, with the burst magnitude and burst duration in- creasing as slope changed from $-50 \%$ to $+50 \%$, as described previously in Gregor et al. [2006]. The LG and MG muscles were consistently active only during upslope walking, whereas during level and downslope walking their EMG bursts were often absent or of low magnitude and duration. This can be explained by the relatively minor role of these muscles in slow level and downslope walking and by electrode location in the fast muscle compartments [Walmsley et al., 1978; English and Letbetter, 1982]. Denervation of SO and LG resulted in dramatic increases in the magnitude and duration of the intact synergists MG and PL within 3 weeks - the values of mean normalized EMG and the burst duration increased by several fold ( $\mathrm{p}<0.05$; fig. 2,3 ). No EMG activity was noticed in SO and LG muscles during the first 3 weeks after denervation. 
Fig. 3. Normalized mean EMG magnitude and burst duration of MG and PL before and 1-3 weeks after denervation of SO and LG muscles during level and slope walking. Mean burst EMG values were normalized to the maximum mean burst EMG found in each cat across all experimental conditions. ${ }^{*} \mathrm{p}<0.05$; significant differences between pre- and postconditions or between postvalues and zero (for MG, mean EMG during downslope condition in which no consistent bursts could be identified). MG data were obtained from 5 cats; numbers of analyzed cycles for downslope, level and upslope conditions before denervation are 0,30 and 47 , and after denervation 71, 113 and 63. PL data were obtained from 2 cats; the corresponding numbers of analyzed cycles are 21,29 and 20 , and 33,53 and 24.

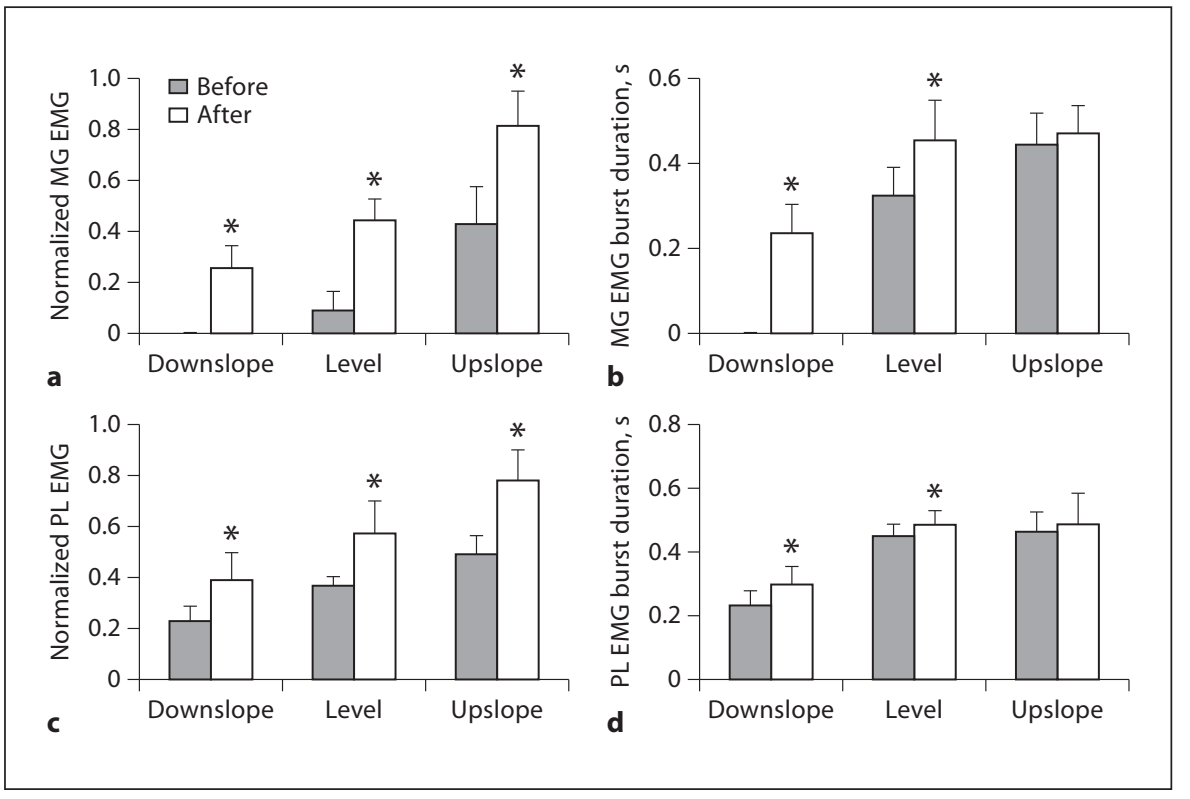

Table 2. Maximum and minimum values of tangential $\left(\mathrm{F}_{\mathrm{x}}\right)$ and normal $\left(\mathrm{F}_{\mathrm{z}}\right)$ ground reaction forces during downslope $(-50 \%)$, level $(0 \%)$ and upslope (50\%) walking before and after denervation of SO and LG muscles

\begin{tabular}{llllll}
\hline & & & Downslope & Level & Upslope \\
\hline $\mathrm{F}_{\mathrm{x}}$ & \multirow{2}{*}{ max. } & before & - & $1.01 \pm 0.18$ & $3.00 \pm 0.41$ \\
& & after & - & $0.71 \pm 0.17^{*}$ & $2.58 \pm 0.34^{*}$ \\
\cline { 3 - 6 } & min. & before & $-1.92 \pm 0.22$ & $-0.72 \pm 0.20$ & - \\
& & after & $-1.60 \pm 0.16^{*}$ & $-0.63 \pm 0.16^{*}$ & - \\
\hline $\mathrm{F}_{\mathrm{z}}$ & \multirow{2}{*}{ max. } & before & $3.87 \pm 0.38$ & $4.79 \pm 0.56$ & $5.17 \pm 0.41$ \\
& & after & $3.19 \pm 0.34^{*}$ & $4.19 \pm 0.32^{*}$ & $4.80 \pm 0.33^{*}$
\end{tabular}

Data are means $\pm \mathrm{SD}$ given in N/kg. Data of 6 cats (total number of analyzed cycles for different walking conditions ranged between 102 and 147).

${ }^{*} \mathrm{p}<0.05$, postdenervation value is significantly different from the corresponding value before denervation.

\section{Changes in Walking Mechanics after Denervation of}

SO and LG Muscles

Joint Angles

Kinematic changes in walking resulting from partial denervation of ankle extensors have been reported by our group previously [Maas et al., 2007, 2010]. The present data set, which overlaps partly with the latter publication (3 cats), demonstrated similar results. Therefore, we do not report kinematic data here and only briefly state the main findings. One to 3 weeks after denervation, the peak ankle dorsiflexion angle increased by $20-30^{\circ}$, whereas the peak knee flexion angle decreased by $5-10^{\circ}$ in midstance of walking on level and sloped surfaces. As a result, the stretch magnitude of MTU of SO, LG and MG (computed using a geometric hindlimb model and recorded joint angles) [Goslow et al., 1973] during the first part of stance increased up to $5 \mathrm{~mm}$ compared to predenervation (an increase of $>50 \%$ ).

\section{Ground Reaction Forces}

Denervation of SO and LG did not change the general pattern of ground reaction forces applied to the hindlimb. Before and shortly after denervation, the tangential forces changed from decelerating (directed opposite to cat walking direction) during downslope walking to decelerating in early stance and accelerating in late stance during level walking and to only accelerating during upslope walking (table 2; fig. 4). The pattern of the normal forces changed only slightly after denervation. However, denervation resulted in a decrease in the peak magnitude of tangential force during late stance of level (by $0.3 \mathrm{~N} / \mathrm{kg}$; $\mathrm{p}<0.05$ ) and upslope (by $0.42 \mathrm{~N} / \mathrm{kg} ; \mathrm{p}<0.05$ ) walking and in a decrease in the peak magnitude in the normal force (by $0.68,0.6$ and $0.37 \mathrm{~N} / \mathrm{kg}$ during downslope, level and upslope walking, respectively; $\mathrm{p}<0.05$ ) (table 2; fig. 4). 

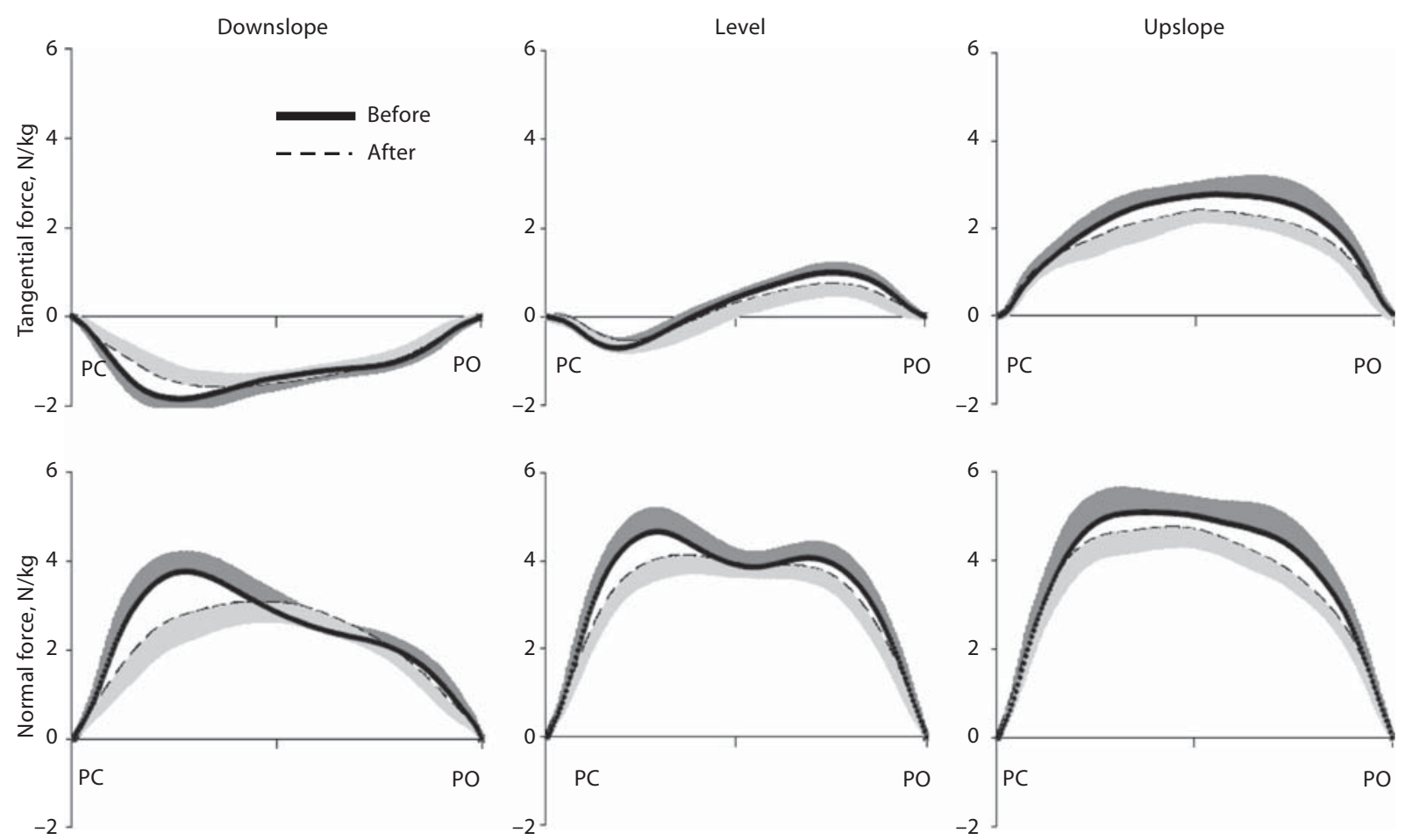

Fig. 4. Mean tangential and normal ground reaction forces applied to the right hindlimb during the stance phase of walking. The forces are shown for downslope, level and upslope walking before (thick continuous line) and 1-3 weeks after (dashed line) denervation of SO and LG. Tangential positive forces correspond to the direction of cat progression. Forces were normalized by mass of the cat. SD values are shown for one direction to avoid clutter. $\mathrm{PC}=$ Paw contact; $\mathrm{PO}=$ paw off. Mean data of 6 cats.

\section{Joint Moments}

Denervation of SO and LG had greater effects on ankle and knee joint moments than on the hip moments. The main result of denervation of two major ankle extensors was the preservation of the peak magnitude of the ankle extensor moment in the stance phase of the 3 slope conditions. The peak moment values after denervation occurred closer to mid-stance with the moment magnitude significantly greater (up to $30 \%$ ) than the pre-injury values at maximum difference $(\mathrm{p}<0.05)$ (table 3 ; fig. 5$)$. The peak knee extensor moments decreased significantly in level and upslope conditions after denervation (for up to $25 \%$; $\mathrm{p}<0.05$ ) (table 3; fig. 5). Denervation of SO and LG also affected the pattern of the knee moment - the flexion phase of the moment in early stance became slightly longer in downslope and level walking (zero-crossing instant shifted by several percents of stance time; $\mathrm{p}<0.05$ ) (table 3; fig. 5).

\section{Joint Power}

Ankle positive power (energy generation rate) increased during the second half of stance in all 3 walking conditions after denervation of SO and LG $(\mathrm{p}<0.05)$ (table 4; fig. 6). This effect was especially apparent during upslope walking where the peak generated power after injury exceeded the control values by $42 \%$. However, the duration of the ankle power generation phase slightly decreased (by 6 and $4 \%$ of stance time for level and upslope conditions; $\mathrm{p}<0.05$ ) (table 4; fig. 6). The peak of ankle negative power (energy absorption rate) also became greater after denervation during level and upslope conditions $(\mathrm{p}<0.05)$ (table 4; fig. 6). The peak rate of energy generation at the knee (positive power) decreased after injury in level and downslope conditions $(\mathrm{p}<0.05)$ (table 4; fig. 6); the knee joint mostly absorbed energy during downslope walking (fig. 6). At the hip joint, denervation mostly influenced the peak negative and positive power, i.e. it decreased in downslope and level conditions and increased in upslope conditions, respectively $(\mathrm{p}<0.05)$ (table 4 ; fig. 6). 
Table 3. Maximum and minimum values of joint moments in stance during downslope (-50\%), level (0\%) and upslope (50\%) walking before and after denervation of SO and LG muscles

\begin{tabular}{|c|c|c|c|c|c|}
\hline Joint & Variable & Denervation & Downslope & Level & Upslope \\
\hline \multirow[t]{6}{*}{ Ankle } & \multirow[t]{2}{*}{$\max$} & before & $0.20 \pm 0.06$ & $0.22 \pm 0.05$ & $0.33 \pm 0.06$ \\
\hline & & after & $0.20 \pm 0.06$ & $0.24 \pm 0.04$ & $0.35 \pm 0.07^{*}$ \\
\hline & \multirow{2}{*}{$\begin{array}{l}\text { values at max. } \\
\text { difference }\end{array}$} & before & $0.11 \pm 0.05$ & $0.15 \pm 0.04$ & $0.23 \pm 0.06$ \\
\hline & & after & $0.16 \pm 0.07^{*}$ & $0.20 \pm 0.03^{*}$ & $0.29 \pm 0.06^{*}$ \\
\hline & \multirow{2}{*}{$\mathrm{T}_{0 \text {-crossing }}$} & before & $88 \pm 10$ & $91 \pm 6$ & $94 \pm 3$ \\
\hline & & after & $88 \pm 9$ & $96 \pm 2^{*}$ & $96 \pm 2^{*}$ \\
\hline \multirow[t]{6}{*}{ Knee } & \multirow[t]{2}{*}{$\max$} & before & $0.20 \pm 0.05$ & $0.22 \pm 0.04$ & $0.20 \pm 0.05$ \\
\hline & & after & $0.19 \pm 0.08$ & $0.18 \pm 0.03^{*}$ & $0.15 \pm 0.03^{*}$ \\
\hline & \multirow[t]{2}{*}{$\min }$. & before & $-0.03 \pm 0.01$ & $-0.04 \pm 0.01$ & $-0.09 \pm 0.04$ \\
\hline & & after & $-0.03 \pm 0.01$ & $-0.04 \pm 0.02$ & $-0.10 \pm 0.05$ \\
\hline & \multirow[t]{2}{*}{$\overline{\mathrm{T}_{0 \text {-crossing }}}$} & before & $11 \pm 6$ & $13 \pm 5$ & $27 \pm 8$ \\
\hline & & after & $19 \pm 16^{*}$ & $14 \pm 7^{*}$ & $33 \pm 9$ \\
\hline \multirow[t]{6}{*}{ Hip } & \multirow[t]{2}{*}{$\max$} & before & $0.07 \pm 0.02$ & $0.12 \pm 0.03$ & $0.39 \pm 0.08$ \\
\hline & & after & $0.07 \pm 0.03$ & $0.11 \pm 0.04^{*}$ & $0.37 \pm 0.10$ \\
\hline & \multirow{2}{*}{$\overline{\min }}$. & before & $-0.26 \pm 0.03$ & $-0.18 \pm 0.04$ & $-0.16 \pm 0.05$ \\
\hline & & after & $-0.25 \pm 0.07$ & $-0.18 \pm 0.04$ & $-0.15 \pm 0.05^{*}$ \\
\hline & \multirow{2}{*}{$\mathrm{T}_{0 \text {-crossing }}$} & before & $23 \pm 7$ & $47 \pm 17$ & $68 \pm 5$ \\
\hline & & after & $26 \pm 8^{*}$ & $43 \pm 12^{*}$ & $70 \pm 11^{*}$ \\
\hline
\end{tabular}

Data are means $\pm \mathrm{SD}$ given in $\mathrm{Nm} / \mathrm{kg}$. $\mathrm{T}_{0 \text {-crossing }}=$ Time instance (in $\%$ of stance time) when the moment crosses zero. Values at maximum difference occurred at the instant indicated by arrows in figure 5 . Data of 5 cats (cat No. 3 was excluded from the data set due to its atypical kinematic patterns); total number of analyzed cycles for different walking conditions ranged between 52 and 116 .

${ }^{*} \mathrm{p}<0.05$, postdenervation value is significantly different from the corresponding value before denervation.

\section{Discussion}

The goal of this study was to examine joint moment and power at the ankle, knee and hip joints after denervation of two major ankle extensors, SO and LG. Based on previously reported kinematic and EMG data, we hypothesized that short-term compensatory changes in movement mechanics in response to paralysis of two ankle extensors enable the motor system to maximally preserve mechanical output of the ankle. Our major findings are consistent with the hypothesis. First, during level and slope walking within 1-3 weeks after injury, the peak ankle extensor moments did not decrease and the moment magnitude in mid-stance became greater than that before injury. Second, after injury, the ankle joint moment during the push-off period of stance generated more mechanical energy and at a greater rate than before the injury. The above results cannot be explained by slightly slower walking speed after denervation in several walking conditions (table 1) because MG and PL EMG activ- ity (fig. 2,3) as well as the ankle moment and power magnitude (tables 3, 4; fig. 5,6) are expected to decrease at slower speeds. In the following discussion, we propose several explanations for these observations.

\section{Activity Enhancement of Intact Synergists}

Partial denervation of ankle extensors or knee flexors leads to enhanced activation of intact synergists (see Introduction). Consistent with these observations is a drastic increase in the EMG magnitude of MG with a smaller increase in PL after SO-LG nerve cut observed in this study (fig. 2, 3). Given a nearly linear relation between EMG and force of MG measured during level and slope walking [Kaya et al., 2003], such changes in EMG of MG are expected to increase the moment of force of this muscle at the ankle by several times. The increase in duration of MG and PL bursts after SO-LG nerve cut (fig. 2, 3) could also contribute to the shift of the ankle momenttime profile to the right, i.e. later in stance (fig. 5). Are the rise in activity and the moment of MG and PL sufficient 
Table 4. Maximum and minimum values of joint power in stance during downslope (-50\%), level (0\%) and upslope (50\%) walking before and after denervation of SO and LG muscles

\begin{tabular}{|c|c|c|c|c|c|}
\hline Joint & Variable & Denervation & Downslope & Level & Upslope \\
\hline \multirow[t]{6}{*}{ Ankle } & \multirow[t]{2}{*}{$\max }$. & before & $0.11 \pm 0.08$ & $0.26 \pm 0.06$ & $0.55 \pm 0.13$ \\
\hline & & after & $0.22 \pm 0.09^{*}$ & $0.39 \pm 0.10^{*}$ & $0.78 \pm 0.21^{*}$ \\
\hline & \multirow[t]{2}{*}{$\min }$. & before & $-0.92 \pm 0.32$ & $-0.39 \pm 0.16$ & $-0.19 \pm 0.17$ \\
\hline & & after & $-1.03 \pm 0.36$ & $-0.50 \pm 0.16^{*}$ & $-0.45 \pm 0.25^{*}$ \\
\hline & \multirow[t]{2}{*}{$\mathrm{T}_{0 \text {-crossing }}$} & before & $52 \pm 9$ & $32 \pm 5$ & $22 \pm 4$ \\
\hline & & after & $54 \pm 6$ & $38 \pm 6^{*}$ & $26 \pm 4^{*}$ \\
\hline \multirow[t]{4}{*}{ Knee } & \multirow[t]{2}{*}{$\max }$. & before & $0.30 \pm 0.19$ & $0.50 \pm 0.16$ & $0.50 \pm 0.12$ \\
\hline & & after & $-0.02 \pm 0.10^{*}$ & $0.25 \pm 0.10^{*}$ & $0.46 \pm 0.12$ \\
\hline & \multirow[t]{2}{*}{$\overline{\min } .^{1}$} & before & $-0.29 \pm 0.20$ & $-0.11 \pm 0.07$ & $-0.04 \pm 0.03$ \\
\hline & & after & $-0.10 \pm 0.13^{*}$ & $-0.03 \pm 0.04^{*}$ & $-0.06 \pm 0.05^{*}$ \\
\hline \multirow[t]{6}{*}{ Hip } & \multirow[t]{2}{*}{$\max .^{1}$} & before & $0.08 \pm 0.04$ & $0.17 \pm 0.06$ & $0.62 \pm 0.36$ \\
\hline & & after & $0.13 \pm 0.08^{*}$ & $0.16 \pm 0.04$ & $0.91 \pm 0.50^{*}$ \\
\hline & \multirow[t]{2}{*}{ min. } & before & $-0.70 \pm 0.19$ & $-0.52 \pm 0.13$ & $-0.37 \pm 0.17$ \\
\hline & & after & $-0.50 \pm 0.23^{*}$ & $-0.34 \pm 0.07^{*}$ & $-0.23 \pm 0.13$ \\
\hline & \multirow[t]{2}{*}{$\overline{\mathrm{T}_{0 \text {-crossing }}}$} & before & - & - & $68 \pm 5$ \\
\hline & & after & - & - & $72 \pm 10^{*}$ \\
\hline
\end{tabular}

Data are means $\pm \mathrm{SD}$ given in $\mathrm{W} / \mathrm{kg}$. $\mathrm{T}_{0 \text {-crossing }}=$ Time instance (in $\%$ of stance time) when the power crosses zero. Data of 5 cats (cat No. 3 was excluded from the data set due to its atypical walking patterns); total number of analyzed cycles for different walking conditions ranged between 92 and 156 .

${ }^{*} \mathrm{p}<0.05$, postdenervation value significantly different from the corresponding value before denervation.

${ }^{1}$ First minimum or maximum value in stance.

to fully account for the ankle moment changes after paralysis of SO and LG muscles? During level and slope walking with slow to medium speeds, $0.4-0.7 \mathrm{~m} / \mathrm{s}$ (as in this study), the contribution of SO force to the total Achilles tendon force and the ankle extensor moment may be greater or comparable with the contribution of the two gastrocnemius heads and PL [Fowler et al., 1993; Gregor et al., 2001; Kaya et al., 2003]. Even at maximum walking speeds close to walk-trot transition speeds $(1.2 \mathrm{~m} / \mathrm{s} ; 2-3$ times greater than in the present study) at which the gastrocnemius motor unit recruitment and developed force are much higher [Walmsley et al., 1978], the summed contribution of the two gastrocnemius heads to the peak Achilles tendon force does not exceed 50\% [Herzog et al., 1994]; the contributions of each MG and LG head could be approximately $25 \%$. The other $50 \%$ of the peak Achilles tendon force is provided by SO and PL. Based on the above discussion, one can assume that during uninjured walking in conditions and with speeds investigated in this study, the contribution of SO force to the ankle moment can be between 25 and $60 \%$ and the individual contributions of LG, MG and PL between 13 and 25\%. This means that even at the lowest possible contribution of SO to the ankle extension moment, 25\% (SO must contribute much more than that during level and downslope conditions) [Walmsley et al., 1978; Gregor et al., 2001; Kaya et al., 2003] denervation of SO and LG would eliminate $50 \%$ of the peak ankle extension moment. Doubling the activity of intact MG and PL could only barely compensate for this loss. Another ankle extensor, flexor hallucis longus, can exert an extensor moment at the ankle as strong as the SO muscle [Lawrence et al., 1993]. However, whether this mostly postural muscle with a relatively small moment arm at the ankle (up to 7 times smaller compared to MG-LG and PL) [Young et al., 1993; Burkholder and Nichols, 2004] increases its activity after LG-SO denervation, and hence, can contribute effectively to ankle extensor moment during locomotion, is unknown. The fact that ankle yield in early stance increases substantially after denervation of two ankle extensors [Maas et al., 2007, 2010] suggests that the active moment at the ankle produced by MG, PL and flexor hallucis longus does not suffice. Thus, other mechanisms are likely contributing to the high ankle extensor moment after injury. 

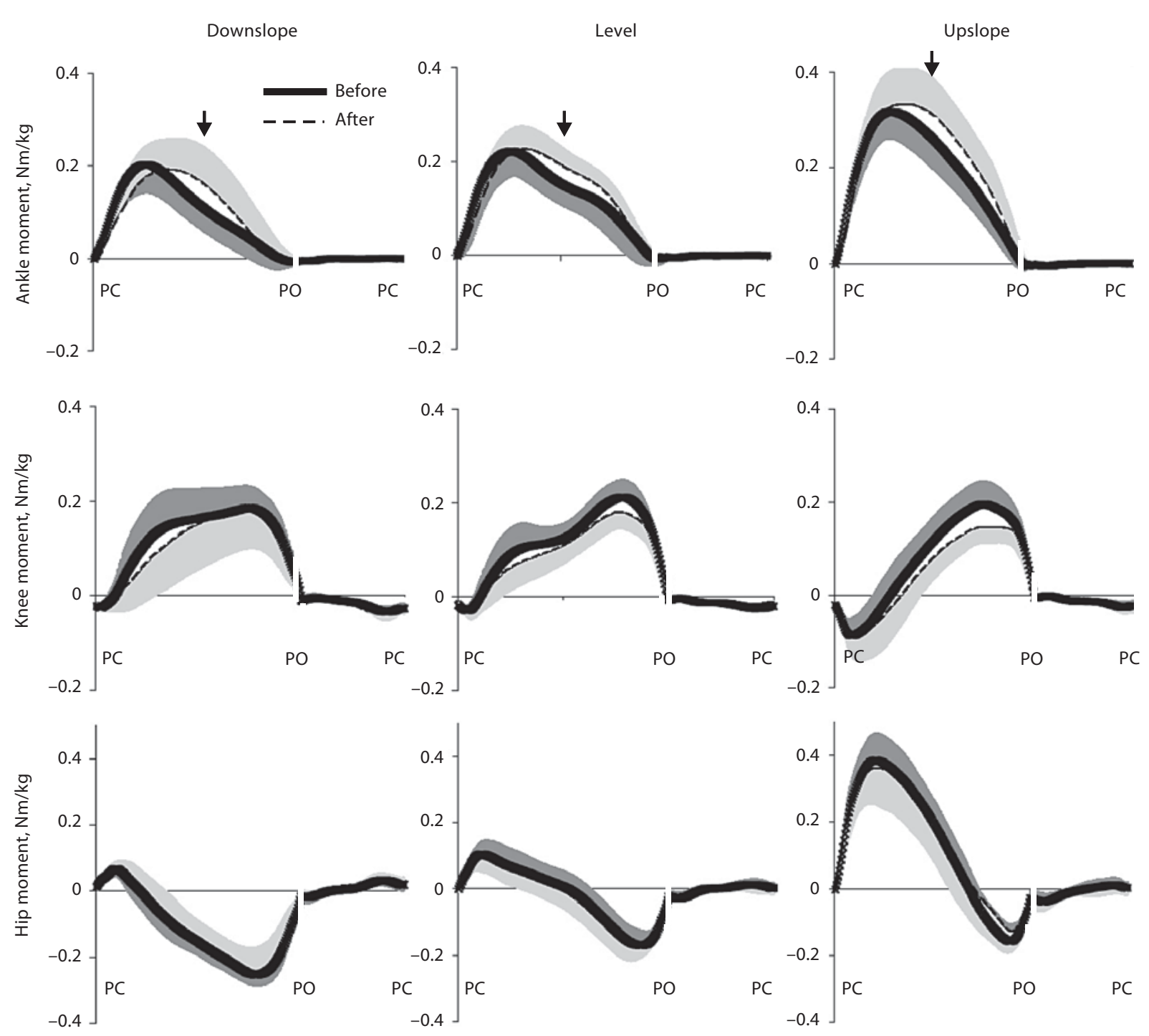

Fig. 5. Mean moments of force at 3 hindlimb joints during downslope, level and upslope walking before (thick continuous line) and 1-3 weeks after (dashed line) denervation of SO and LG muscles. Positive values correspond to extensor moments. Moments were normalized by mass of the cat. SD values are shown for one direction to avoid clutter. The arrows indicate time in- stances of the maximum difference between the pre- and postdenervation moments for the ankle joint (table 3). PC = Paw contact; $\mathrm{PO}=$ paw off. Stance and swing times were normalized separately which is indicated by interruption of the time axis (see stance and swing times in table 1). Mean data of 5 cats.

\section{Contribution of Passive Tissues to Ankle Extensor \\ Moment}

Contributions of passive tissues to resultant ankle joint moment are relatively small within the joint range of motion typical for normal locomotion. The measured passive ankle moment as a function of ankle and knee joint angles in the cat [Maas and Sandercock, 2008, fig. 3] predicts the passive ankle moment contribution of approximately $0.1,0.12$ and $0.1 \mathrm{Nm}$ (or 13, 16 and $9 \%$ of peak ankle extension moment during walking) [Gregor et al., 2006] (table 3) at mid-stance of downslope, level and upslope walking, respectively. After partial denervation of ankle extensors and the subsequent changes in ankle and knee joint angles in mid-stance [Maas et al., 2007, 

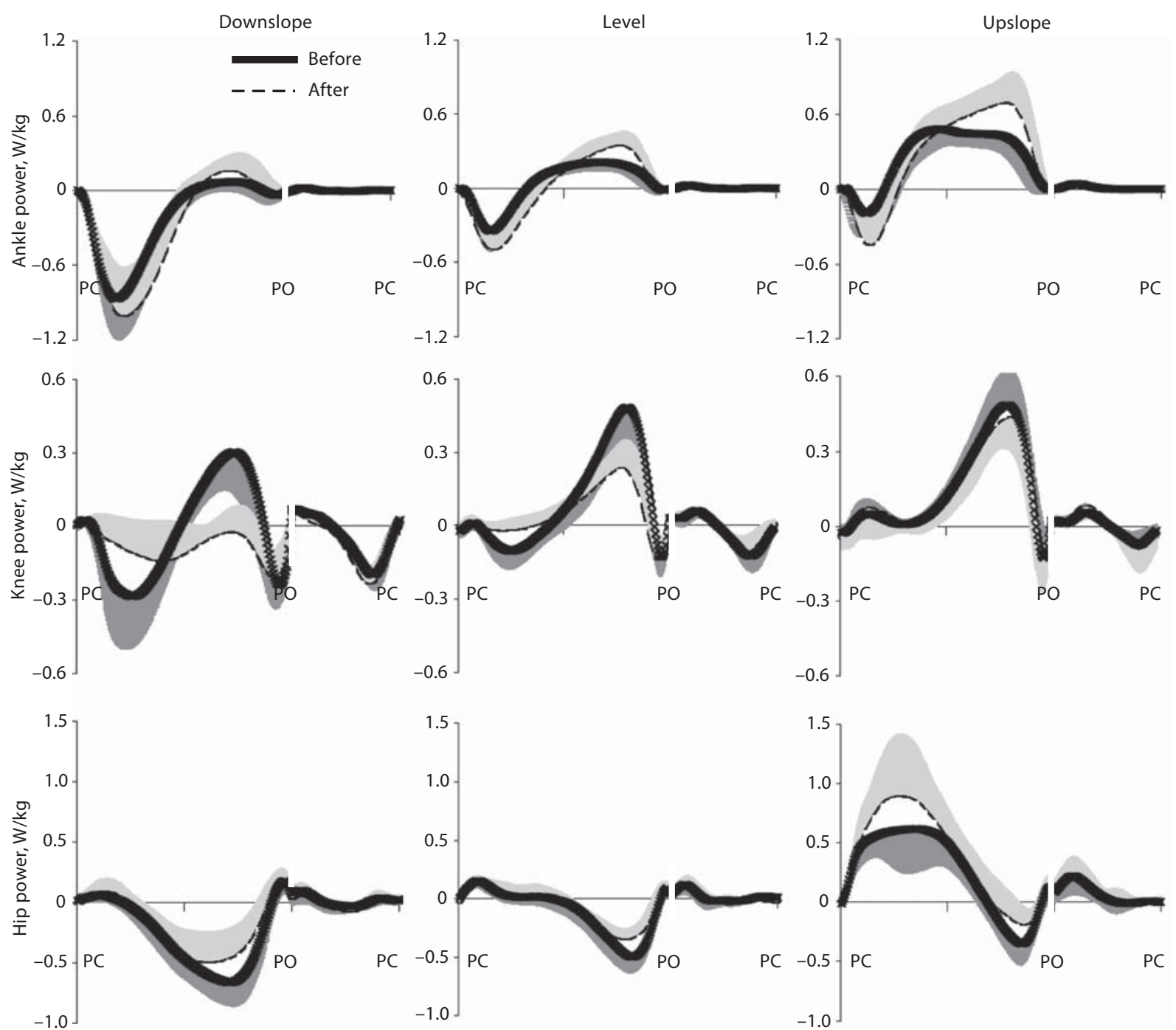

Fig. 6. Mean power at 3 hindlimb joints during downslope, level and upslope walking before (thick continuous line) and 1-3 weeks after (dashed line) denervation of SO and LG muscles. Positive and negative powers correspond to mechanical energy generation and absorption, respectively. Powers were normalized by mass of the cat. SD values are shown for one direction to avoid clutter. $\mathrm{PC}=$ Paw contact; $\mathrm{PO}=$ paw off. Stance and swing times were normalized separately which is indicated by interruption of the time axis (see stance and swing times in table 1). Mean data of 5 cats. fig. 3-5], the passive ankle moment is expected to increase substantially to estimated $0.4,0.3$ and $0.35 \mathrm{Nm}$ (or 60,40 and $30 \%$ of peak ankle moment) (table 3 ).

The contribution of passive tissues to ankle extensor moment was also examined qualitatively in 3 cats of the present study ( 2 cats with denervated LG and SO and 1 intact cat). The cats were sedated (dexmedetomidine, 40-
$60 \mu \mathrm{g} / \mathrm{kg}$, s.c.), placed on the left side of the body, and the right hindlimb was positioned so as to approximate leg posture in mid-stance during level walking after denervation of SO and LG (ankle angle approximately $70^{\circ}$, knee angle approximately $120^{\circ}$ and hip angle approximately $120^{\circ}$ ). Force application to the distal tarsals in the direction of the hip joint by the hand whilst restricting move- 
ment of the pelvis revealed a very high hindlimb resistance which did not allow any significant ankle dorsiflexion. No difference in resistance was noticed among the 3 animals. When the knee joint was placed at a flexion angle $<50^{\circ}$, dorsiflexion could continue without resistance.

Thus, the contribution of passive tissues to the ankle extensor moment appears to increase substantially after denervation of SO and LG due to a greater ankle dorsiflexion and a smaller knee flexion during stance, and hence, higher MTU lengths [Maas et al., 2010]. This ankle resistance to dorsiflexion is likely caused by passive insufficiency of two-joint muscles crossing the ankle and knee (LG, MG and PL) (fig. 1b, c).

\section{Tendon Action of Two-Joint Muscles}

The stifflink between the foot and thigh during stance possibly created by passive denervated LG and active MG and PL has the potential for transfer of mechanical energy between the ankle and knee joints which can assist the injured ankle in absorption and generation of energy (so-called tendon action of two-joint muscles); see e.g., Lombard [1903] and Prilutsky and Zatsiorsky [1994]. During the yield phase of walking, the foot touching the ground tends to rotate towards flexion under the action of ground reaction forces (fig. 1b, c). The foot rotation displaces the attachment points of LG, MG and PL on the calcaneus downwards. If these muscles resist their length change either passively (LG) and/or by active contraction (MG and PL), they transmit calcaneus motion to the femur (as a towline) forcing the knee joint to flex by applying tension at the muscle origin on the femur. The knee flexion is resisted by knee extensors, and if knee flexion occurs, the knee extensors absorb energy originating partly from the ankle flexion. Thus, the tendon action of LG, MG and PL could enable intact and larger knee extensors to assist injured ankle extensors in the necessary dissipation of mechanical energy.

An increase in negative power at the ankle and a decrease in negative power at the knee during the yield phase of level and upslope walking after partial denervation of ankle extensors (fig. 6) are consistent with the above scenario of tendon action of LG, MG and PL and transfer of mechanical energy from the ankle to the knee; for more elaborate explanations of this mechanism, see Prilutsky and Zatsiorsky [1994] and Prilutsky et al. [1996]. Force measurements of cat gastrocnemius and PL and kinematic analysis during normal level walking revealed that the amount of energy transferred from the ankle to the knee during the yield phase of stance was $7-22 \%$ of negative work done by the ankle moment (area under the negative power; fig. 6) [Prilutsky et al., 1996]. It is likely that after partial denervation of ankle extensors and diminishing their ability to dissipate energy, the amount of energy transfer from ankle to knee is increased. This hypothesis will be tested in the future by measuring forces of the two-joint muscles and employing the approach described in Prilutsky et al. [1996].

During the propulsion phase in stance, the tendon action of LG, MG and PL could promote additional ankle extension by transferring energy generated by intact knee extensors to the ankle. In this possible scenario, knee extension produced by vasti and rectus femoris muscles displaces the origin of LG, MG and PL on the femur upwards, which through the tendon (towline-like) action pulls on the calcaneus and assists in ankle extension (fig. 1b, c). Thus, mechanical energy generated by knee extensors would be transmitted distally through twojoint LG, MG and PL and used in ankle extension. If the two-joint muscles are shortening during this phase, they also generate energy and deliver it to the ankle. An increase in ankle power and energy generation accompanied by a reduction in knee positive power during the propulsion phase of stance (fig. 6) is also consistent with the above explanation. The amount of mechanical energy transmitted from knee to ankle after partial denervation of ankle extensors could increase compared to the reported values for normal level walking (7-14\% of positive work of ankle moment) [Prilutsky et al., 1996] given the diminished abilities of ankle extensors to generate energy and the observed increase in positive ankle power and work (fig. 6).

The crural fascia (originating proximally from the distal hamstrings, overlying the gastrocnemius and terminating on the calcaneus) could also contribute to energy transfer from knee to ankle, resulting from the injuryrelated enhancement of knee extension and ankle dorsiflexion in stance and thus fascia stretch [Carrasco and English, 1999; Stahl, 2010].

\section{Concluding Remarks}

Changes in mechanics of locomotion after peripheral nerve injury of selected ankle extensors obtained in this study appear to preserve mechanical output of the injured ankle joint. These changes could result from unmodified spinal reflex responses of intact ankle extensors to changed kinematics (e.g., stretch of MG fascicles) [Maas et al., 2010] in a manner similar to reflex actions stabilizing locomotion during external perturbations. 
This would require such organization of spinal reflexes that would automatically counteract any possible trauma of the peripheral nervous and musculoskeletal systems and promote functionally appropriate responses.

Other attractive mechanisms promoting the observed locomotor compensations may be that the nervous system modulates reflex responses and central drive to intact muscles to compensate for a particular motor deficit. This idea is supported by reported changes in gains of proprioceptive feedback [Pearson and Misiaszek, 2000; Frigon and Rossignol, 2008; Donelan et al., 2009] and central drive to intact synergists [Gritsenko et al., 2001; Maas et al., 2010] after peripheral nerve injury. The adap- tive locomotor changes must rely on proprioceptive feedback and could be mediated by neural plasticity at both spinal [Frigon and Rossignol, 2008] and supraspinal levels [Lundborg, 2000].

\section{Acknowledgements}

We would like to thank Bradley J. Farrell for his help with data collection and analysis and Arthur W. English for his assistance with nerve cut and repair. This work was supported by National Institutes of Health grants HD-032571 and NS-048844 and by the Center for Human Movement Studies at Georgia Institute of Technology.

\section{References}

Abelew, T.A., M.D. Miller, T.C. Cope, T.R. Nichols (2000) Local loss of proprioception results in disruption of interjoint coordination during locomotion in the cat. J Neurophysiol 84: 2709-2714.

Bobbert, M.F., P.A. Huijing, G.J. van Ingen Schenau (1986) An estimation of power output and work done by the human triceps surae muscle-tendon complex in jumping. J Biomech 19: 899-906.

-Buchthal, F., V. Kuhl (1979) Nerve conduction, tactile sensibility, and the electromyogram after suture or compression of peripheral nerve: a longitudinal study in man. J Neurol Neurosurg Psychiatry 42: 436-451.

Bulgakova, M., B.J. Farrell, R.J. Gregor, B.I. Prilutsky (2010) Short-term motor adaptation to denervation of feline selected ankle extensor muscles results in preservation of ankle mechanical output during locomotion (online program No. 787.9). San Diego, Society for Neuroscience.

Burkholder, T.J., T.R. Nichols (2004) Three-dimensional model of the feline hindlimb. J Morphol 261: 118-129.

-Carrasco, D.I., A.W. English (1999) Mechanical actions of compartments of the cat hamstring muscle, biceps femoris. Prog Brain Res 123: 397-403.

Chalfoun, C.T., G.A. Wirth, G.R. Evans (2006) Tissue engineered nerve constructs: where do we stand? J Cell Mol Med 10: 309-317.

Chang, Y.H., A.G. Auyang, J.P. Scholz, T.R. Nichols (2009) Whole limb kinematics are preferentially conserved over individual joint kinematics after peripheral nerve injury. J Exp Biol 212: 3511-3521.

Cope, T.C., S.J. Bonasera, T.R. Nichols (1994) Reinnervated muscles fail to produce stretch reflexes. J Neurophysiol 71: 817-820.

Donelan, J.M., D.A. McVea, K.G. Pearson (2009) Force regulation of ankle extensor muscle activity in freely walking cats. J Neurophysiol 101: 360-371.

\section{English, A.W. (2005) Enhancing axon regenera- tion in peripheral nerves also increases func- tionally inappropriate reinnervation of tar- gets. J Comp Neurol 490: 427-441. \\ English, A.W., W.D. Letbetter (1982) A histo- chemical analysis of identified compart- ments of cat lateral gastrocnemius muscle. Anat Rec 204: 123-130. \\ English, A.W., W. Meador, D.I. Carrasco (2005) Neurotrophin- $4 / 5$ is required for the early growth of regenerating axons in peripheral nerves. Eur J Neurosci 21: 2624-2634. \\ Fowler, E.G., R.J. Gregor, J.A. Hodgson, R.R. Roy (1993) Relationship between ankle muscle and joint kinetics during the stance phase of locomotion in the cat. J Biomech 26: 465- 483.}

Frigon, A., S. Rossignol (2008) Locomotor and reflex adaptation after partial denervation of ankle extensors in chronic spinal cats. J Neurophysiol 100: 1513-1522.

Goslow, G.E., Jr., R.M. Reinking, D.G. Stuart (1973) The cat step cycle: hind limb joint angles and muscle lengths during unrestrained locomotion. J Morphol 141: 1-41.

Gregor, R.J., B.I. Prilutsky, T.R. Nichols, W. Smith (2003) EMG output in reinnervated medial gastrocnemius muscle during locomotion in the cat (online program No. 493.8). New Orleans, Society for Neuroscience.

Gregor, R.J., D.W. Smith, B.I. Prilutsky (2006) Mechanics of slope walking in the cat: quantification of muscle load, length change, and ankle extensor EMG patterns. J Neurophysiol 95: 1397-1409.

Gregor, J.R., J.L. Smith, D.W. Smith, A. Oliver, B.I. Prilutsky (2001) Hindlimb kinetics and neural control during slope walking in the cat: unexpected findings. J Appl Biomech 17: 277-286.

Gritsenko, V., V. Mushahwar, A. Prochazka (2001) Adaptive changes in locomotor control after partial denervation of triceps surae muscles in the cat. J Physiol 533: 299-311.
-Herzog, W., V. Zatsiorsky, B.I. Prilutsky, T.R Leonard (1994) Variations in force-time histories of cat gastrocnemius, soleus and plantaris muscles for consecutive walking steps. J Exp Biol 191: 19-36.

Hoy, M.G., R.F. Zernicke (1985) Modulation of limb dynamics in the swing phase of locomotion. J Biomech 18: 49-60.

-Hu, P., E.M. McLachlan (2003) Selective reactions of cutaneous and muscle afferent neurons to peripheral nerve transection in rats. J Neurosci 23: 10559-10567.

Kaya, M., T. Leonard, W. Herzog (2003) Coordination of medial gastrocnemius and soleus forces during cat locomotion. J Exp Biol 206: 3645-3655

Kline, D.G. (1990) Surgical repair of peripheral nerve injury. Muscle Nerve 13: 843-852.

Lawrence, J.H., 3rd, T.R. Nichols, A.W. English (1993) Cat hindlimb muscles exert substantial torques outside the sagittal plane. J Neurophysiol 69: 282-285.

Lombard, W.P. (1903) The action of two-joint muscles. Am Phys Educ Rev 9: 141-145.

Lundborg, G. (2000) Brain plasticity and hand surgery: an overview. J Hand Surg Br 25: 242-252.

Lundborg, G., B. Rosen (2007) Hand function after nerve repair. Acta Physiol (Oxf) 189: 207-217.

Maas, H., R.J. Gregor, E.F. Hodson-Tole, B.J. Farrell, A.W. English, B.I. Prilutsky (2010) Locomotor changes in length and EMG activity of feline medial gastrocnemius muscle following paralysis of two synergists. Exp Brain Res 203: 681-692.

Maas, H., B.I. Prilutsky, T.R. Nichols, R.J. Gregor (2007) The effects of self-reinnervation of cat medial and lateral gastrocnemius muscles on hindlimb kinematics in slope walking. Exp Brain Res 181: 377-393. 
Maas, H., T.G. Sandercock (2008) Are skeletal muscles independent actuators? Force transmission from soleus muscle in the cat. J Appl Physiol 104: 1557-1567.

Madison, R.D., G.A. Robinson, S.R. Chadaram (2007) The specificity of motor neurone regeneration (preferential reinnervation). Acta Physiol (Oxf) 189: 201-206.

Manter, J.T. (1938) The dynamics of quadrupedal walking. J Exp Biol 15: 522-540.

McFadyen, B.J., S. Lavoie, T. Drew (1999) Kinetic and energetic patterns for hindlimb obstacle avoidance during cat locomotion. Exp Brain Res 125: 502-510.

>Noble, J., C.A. Munro, V.S. Prasad, R. Midha (1998) Analysis of upper and lower extremity peripheral nerve injuries in a population of patients with multiple injuries. J Trauma 45: $116-122$.

Pearson, K.G., K. Fouad, J.E. Misiaszek (1999) Adaptive changes in motor activity associated with functional recovery following muscle denervation in walking cats. J Neurophysiol 82: 370-381.

Pearson, K. G., J. E. Misiaszek (2000) Use-dependent gain change in the reflex contribution to extensor activity in walking cats. Brain Res 883: 131-134.
Portincasa, A., G. Gozzo, D. Parisi, L. Annacontini, A. Campanale, G. Basso, A. Maiorella (2007) Microsurgical treatment of injury to peripheral nerves in upper and lower limbs: a critical review of the last 8 years. Microsurgery 27: 455-462.

Prilutsky, B.I., W. Herzog, T. Leonard (1996) Transfer of mechanical energy between ankle and knee joints by gastrocnemius and plantaris muscles during cat locomotion. J Biomech 29: 391-403.

Prilutsky, B.I., H. Maas, T.R Nichols, R.J. Gregor (2006) Effects of self-reinnervation of selected cat ankle extensors on their activity and hindlimb mechanics in slope walking (online program No. 648.19). Atlanta, Society for Neuroscience.

Prilutsky, B.I., M.G. Sirota, R.J. Gregor, I.N. Beloozerova (2005) Quantification of motor cortex activity and full-body biomechanics during unconstrained locomotion. J Neurophysiol 94: 2959-2969.

Prilutsky, B.I., V.M. Zatsiorsky (1994) Tendon action of two-joint muscles: transfer of me chanical energy between joints during jumping, landing, and running. J Biomech 27: 2534.

Scholz, T., A. Krichevsky, A. Sumarto, D. Jaffurs, G.A. Wirth, K. Paydar, G.R. Evans (2009) Peripheral nerve injuries: an international survey of current treatments and future perspectives. J Reconstr Microsurg 25: 339-344.
Stahl, V.A. (2010) A biomechanical analysis of the crural fascia in the cat hindlimb; doctoral disseration, Georgia Institute of Technology, Atlanta.

Sunderland, S. (1990) The anatomy and physiology of nerve injury. Muscle Nerve 13: 771784.

Tachibana, A., D.A. McVea, J.M. Donelan, K.G. Pearson (2006) Recruitment of gastrocnemius muscles during the swing phase of stepping following partial denervation of knee flexor muscles in the cat. Exp Brain Res 169: 449-460.

Walmsley, B., J.A. Hodgson, R.E. Burke (1978) Forces produced by medial gastrocnemius and soleus muscles during locomotion in freely moving cats. J Neurophysiol 41: $1203-$ 1216

Welin, D., L.N. Novikova, M. Wiberg, J.O. Kellerth, L.N. Novikov (2008) Survival and regeneration of cutaneous and muscular afferent neurons after peripheral nerve injury in adult rats. Exp Brain Res 186: 315-323.

Young, R.P., S.H. Scott, G.E. Loeb (1993) The distal hindlimb musculature of the cat: multiaxis moment arms at the ankle joint. Exp Brain Res 96: 141-151. 